\title{
A Study of Influence of Gender differences of the Children of Working \& Non-Working Mothers in Perception of Parental Behaviour
}

\author{
Ms Bhawana Bhatt \\ Research Scholar, Birla Campus. H.N.B. Garhwal University, Srinagar.
}

\begin{abstract}
An attempt has been made to investigate the influence of gender differences of the children of the working and non-working mothers in perception of parental behaviour. The sample consisted of 180 boys and girls studying in the institutions of Dehradun District, Uttarakand. The perception of parental behaviour(mother's behaviour) was assesses with the help of PCRQ developed by Dr. R.A. Sing (1981). The data were analysed by Mean, S.D. and 't' ratio. The results indicate that parental behaviour (mother's behaviour) changes with respect to gender. It was found that influence of gender difference of the children of working and non-working mothers different. However, significant difference was observed in non-working mothers behaviour on dominating, rejecting and disciplining variables for boys and girls. It was also found that girls perceived their working and non-working mothers more loving than boys.
\end{abstract}

\section{Introduction}

The most characteristic feature of all close relationship is interdependence, an interpersonal association in which two people consistently and reciprocally influence one another's lives and focus their thoughts and emotions on one another. And all these close interdependent relationship begin in the family. Family is one of the basic social institutions its plays a pivotal role in shaping the personality structure of an individual. A person is socialized in the family. Therefore, its naturally plays a significant role in determining the behaviour pattern which child will exhibit.

Researches show that home and child rearing practices influence the personality development of the child (Hurlock, 1959 ; Mccord et al. 1992 ; Schaefer, 1969 and Desousa, 1970). Child rearing practices are influenced by culture of the community and hence these vary from culture to culture. An individual is obviously both a biological and social fact. Biological predispositions interact with the impact of social experiences which in turn shape the psychological make up of the person. The amount of interaction between parent and young child does not consistently depend upon the gender of the child.

The kind of family in which children are grown up and it's effect on their development can be determined by the kind of relationship child has with his mother Because a women plays an important role in family. The role of female in the society has been remarkably changed after the technical and cultural changes in the society. Two earner families are now very much prevalent due to increase in the number of employed mother (Hayghe, 1982). It is the result of employment of both husband and wife that family roles of men and women are also changing (Pleck, 1985). It is therefore reasonable to expect that home environment in dual and single earner families will differ. Working women feel satisfied by doing work but face special challenges as she try to balance work and family responsibilities. Non-working mothers stay at home for most of the time and interfere with the life of their children. This might be cause of family conflict.

Owing to competitiveness in academics children need the presence and help of their parents. Maternal employment can have both kinda of effects, positive or negative on the family environment.

In view of the above, the present study has been undertaken to find out the influence of gender differences of the children of working and non- working women in perception of parental behaviour. Parental behaviour changes to according to conditions of working and non- working situations of mother. According to the official documents' released to mark the "SAARC" that discriminative practices are adopted for female gender in India. Culture of the community and its attitude towards gender influences parental behaviour and there by the development of the child. Moreover, how children of working and non-working women perceive their parental behaviour is more important, accurate and trustworthy than parents perceive about with their children.

\section{Justification of study}

Present study has more behavioural importance. The study will be useful to develop the personality pattern of of the individual. Leosa and Brophy (1972) reported that girls perceived their mothers to more affectionate and more accepting. Two earner families are now very much prevalent due to increase in the 
number of employed mothers ( Hayghe, 1982 ). It is, therefore, reasonable to expect that home environment in dual and single families will differ. So the present study has been taken to find out the influence of gender differences of maternal employment with the children in perception of parental behaviour and compare them with those of the adolescent children of non-working mothers. Dehlem(1970) reported that both sexes viewed their mothers as responsible for the maintenance of family solidarity and for nurturance and emotional support. Hatfield and others(1967) found that mothers were more likely to restrict the independent movement of sons than of daughters.

The study of Baya and Roby (1993) showed that mothers employment had no significant effect on the children's school performance, conduct and stress. Stein(1973) reported that college females with employed mothers had higher educational aspirations than those whose mothers were not working outside the home.

In the light of the above stated researches, the researcher was motivated to find out the influence of gender differences in perception of parental behaviour among children of working and non-working mothers residing in Dehradun district of Uttarakand .

\section{Objectives}

The following objectives were stated for the study:-

1. To study the perceived parental behaviour ( mother's behaviour) dimensions- loving, dominating, rejecting, protecting, punishing and disciplining of the children of working and non-working mothers.

2. To study the differences in the perception of parental behaviour for boys and girls of working and nonworking mothers.

\section{Methodology}

Sample : 180 boys and girls (12-15 years) studying in the institutions of Dehradun , Uttarakhand were taken for the present study.

Tool : The parent-child Relationship Questionnaire(m-Form) developed by R.A. Singh in !981 was used to assess perceived parental behaviour. It consists of six ten-item scales which were prepared to denote specific and observable behaviour. These are Loving, Dominating, Rejecting, Protecting, Punishing, and Disciplining. A separate but identical form for mother (M-form) was prepared for Hindi medium pupils. The 'Yes-No' response categories are provided and to be summed up to yield scores for each scale assigning 1 and 0 marks respectively, but in case of negative items the order of scoring is to be reversed. The internal consistency reliability computed with Spearman-Brown formula ranged from 0.59 to 0.82 .

\section{Procedure :}

Sampled students were administered the PCRQ in single class room session with instruction to recall, their mother's behaviour and answer each item in the respective questionnaire.

\section{Statistical Technique and Interpretation of data :}

Mean and S.D were calculated from the variables of PCRQ (M-Form) for boys and girls of working and non-working mothers separately. The " $\mathrm{t}$ " test was applied for the comparison of groups. The table were interpreted for testing the hypothesis analyzing the results of the study.

Table 1

Comparison of boys and girls on perception of parental behaviour ( working mother's behaviour)

\begin{tabular}{|l|l|l|l|l|l|}
\hline S.No. & Variables & Groups & Mean & S.D. & t \\
\hline 1 & Loving & Boys & 8.40 & 1.16 & 1.019 \\
& & Girls & 10.50 & 12.80 & \\
\hline 2 & Dominating & Boys & 3.5667 & 1.69 & .517 \\
& & Girls & 3.375 & 1.233 & \\
\hline 3 & Rejecting & Boys & 3.30 & 1.84 & 1.73 \\
& & Girls & 2.625 & 1.191 & \\
\hline 4 & Protecting & Boys & 7.133 & 1.814 & 1.695 \\
& & Girls & 10.67 & 12.86 & \\
\hline 5 & Punishing & Boys & 3.266 & 2.148 & 1.945 \\
& & Girls & 2.375 & 1.408 & \\
\hline 6 & Disciplining & Boys & 9.833 & 16.817 & 1.090 \\
& & Girls & 6.4 & 2.56 & \\
\hline
\end{tabular}

Table 1:- Interpretation of data table 1 shows that mean scores on dominating variable are nearly same for bys and girls. It shows that boys and girls both perceived their mother's behaviour as equally dominating while 
mean difference on loving, protecting, punishing and disciplining is high which shows that girls perceived their mothers more loving and protecting in comparison to boys. Further this mean diff is not significant at .01 level. Hence it is concluded that there is no significant difference in working mothers's behaviour on loving and protecting, punishing and disciplining variables. Boys perceived working mothers's behaviour more rejecting and disciplining in comparison to girls.

These results indicate more dominating, rejecting, protecting, punishing and disciplining behaviour working mothers towards boys.

Table 2

Comparison of boys and girls on perception of parental behaviour ( Non-working mother's behaviour)

\begin{tabular}{|c|c|c|c|c|c|}
\hline S.No. & Variables & Groups & Mean & S.D. & $\mathrm{t}$ \\
\hline 1 & Loving & $\begin{array}{l}\text { Boys } \\
\text { Girls } \\
\end{array}$ & \begin{tabular}{|l}
7.257 \\
10.133 \\
\end{tabular} & $\begin{array}{c}1.703 \\
13.44 \\
\end{array}$ & 1.409 \\
\hline 2 & Dominating & $\begin{array}{l}\text { Boys } \\
\text { Girls }\end{array}$ & $\begin{array}{l}4.257 \\
3.022 \\
\end{array}$ & $\begin{array}{l}2.105 \\
1.27 \\
\end{array}$ & $3.02 * *$ \\
\hline 3 & Rejecting & $\begin{array}{l}\text { Boys } \\
\text { Girls }\end{array}$ & $\begin{array}{l}3.942 \\
2.577\end{array}$ & $\begin{array}{l}1.747 \\
1.602\end{array}$ & $3.548 * *$ \\
\hline 4 & Protecting & $\begin{array}{l}\text { Boys } \\
\text { Girls }\end{array}$ & $\begin{array}{l}6.628 \\
6.911\end{array}$ & $\begin{array}{l}1.436 \\
1.928\end{array}$ & 1.50 \\
\hline 5 & Punishing & $\begin{array}{l}\text { Boys } \\
\text { Girls }\end{array}$ & $\begin{array}{l}3.342 \\
4.022\end{array}$ & $\begin{array}{l}1.235 \\
2.544\end{array}$ & 1.55 \\
\hline 6 & Disciplining & $\begin{array}{l}\text { Boys } \\
\text { Girls }\end{array}$ & $\begin{array}{l}8.457 \\
7.173\end{array}$ & $\begin{array}{l}.9185 \\
1.735\end{array}$ & $4.20^{* *}$ \\
\hline
\end{tabular}

$*$ = Significant at 0.05 level

$* *=$ Significant at 0.01 level

Table 2: Interpretation of data table 2 shows that mean scores on protecting behaviour are nearly same for boys and girls. It shows that boys and girls both perceived their mothers behaviour as equally protecting while mean difference for loving and punishing is high which shows that girls perceived their non-working mothers more loving and punishing in comparison to boys. While mean difference in dominating, rejecting and disciplining variable is high which shows that boys perceived their non-working mothers more dominating, rejecting and discipling in comparison to girls. Further this mean difference is significant at 0.01 and 0.05 level. Hence it is concluded that there is significant difference in non-workings mother's behaviour on dominating, rejecting and disciplining behaviour. Boys perceived non-nworking mothers' behaviour more rejecting and dominating in coparison to girls. Wadker and Palasane had also concluded (1987) in their study that girls more satisfied with parent child relationship than boys. Pandy S.K. (2005) had also concluded girls perceived their mothers as more loving and less dominating.

\section{Conclusion}

In view of the above the results follwing conlusions were drawn :

1. Parental (mother's ) behaviour changes with respect to the gender of child.

2. Boys perceived their working mothers' behaviour more rejecting and disciplining in comparison to girls while perception on dominating variable is nearly the same.

3. Girls perceived their working mothers, behaviour more loving and protecting in comparison to boys.

4. Girls perceived their non-working mothers, behaviour more loving and punishing in comparison to boys while perception on protecting variable is nearly the same.

5. Boys perceived their non-working mothers' more dominating, rejecting and disciplining in comparison to girls.

6. Boys of both working and non-working mothers' perceived their behaviour more rejecting and disciplining than girls.

7. Girls of both working and non-working mothers' perceived heir behaviour more loving than boys. 


\section{References}

[1]. Bhargava, Mahesh and Aurora, Saroj (2001): Parental Behaviour, H.P, Bhargava Publishers, Agra Baya and Amal Roby. (1993 ),The Effect of Mother's Employment and Social Class.

[2]. Dissertation Abstract International, 53(10),3443.

[3]. Desai, Neera. (1957): Women in Modern India, Bora and Company publishers, P.Ltd.

[4]. Hayghe, H. (1982). Dual-earner Families: Their Economic and Demographic Characteristics. In J. Alodous(Ed.), two paychecks: life in dual- earner families (27-40) Beverly hills, CA: Sage.

[5]. Pleck, J.h. (1985). Working Wioves/Working husband. Braverly Hills.

[6]. Pandey, S.K. (2005): A study of influence of Gender Differences In Perception Of Parental Behaviour, Indian Educational Review, vol.41, no.2, pp. 118-124.

[7]. Saini, Sarita (2005): Family Environment and Academic Achievement of Aolescent children of Working and Non-working Mothers, Indian Educational Review,vol.41, No.2, pp. 87-95.

[8]. Wadkar, A.J. and Palasane, M.N. (1987) "Sex-differences in child's perception of Parent-child relations". Journal of psychological researches Vol.31, No.3, pp.160-165. 